\title{
Prevalence, serotypes, and antimicrobial resistance of Salmonella isolates from patients with diarrhea in Shenzhen, China
}

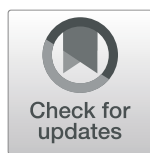

Hongwei Shen ${ }^{1,2}$, Haochuan Chen², Yongxuan Ou², Tingting Huang ${ }^{1}$, Siping Chen ${ }^{1}$, Lintao Zhou ${ }^{3}$, Jinjin Zhang ${ }^{2}$, Qinghua $\mathrm{Hu}^{4}$, Yiwen $\mathrm{Zhou}^{1}$ and Wen Ma ${ }^{1 *}$

\begin{abstract}
Background: Salmonella is one of the main causative agents of diarrhea which results in substantial disease burden. To determine the prevalence, serotype distribution, and antimicrobial resistance profiles of clinical Salmonella isolates in Shenzhen, a 6-year surveillance study was conducted.

Results: A total of 297 (5.7\%) Salmonella strains were isolated from stool samples from 5239 patients. Among the 42 serotypes identified, serotype Typhimurium was the most common one which represented $39.7 \%$ of the isolates (118), followed by serotype Enteritidis (71, 23.9\%), London (12, 4.0\%), 4, 5, 12: i: - (11, 3.7\%), and Senftenberg (8, 2.7\%). A high frequency of resistance was found in ampicillin (70.6\%), piperacillin (64.5\%), tetracycline (63.5\%), and streptomycin (54.3\%). Resistance to ampicillin and tetracycline was observed in $95.3 \%$ of S. Typhimurium isolates; and nalidixic acid in $93.1 \%$ of $S$. Enteritidis isolates. Resistance to 5 or more antimicrobial agents was found in $78.8 \%$ of $S$. Typhimurium and $69.0 \%$ of $S$. Enteritidis isolates. A decreased susceptibility to ciprofloxacin and levofloxacin was associated with amino acid alteration in gyrA gene. Point mutations without amino acid changes were seen in gyrB, parC, and parE genes.

Conclusions: A broad range of serotypes are responsible for Salmonellosis in Shenzhen, with Enteritidis and Typhimurium being the most common serotypes. The high level of antibiotic resistance is of public health significance and ongoing monitoring combined with rational use of antibiotics are recommended. Point mutations in gyrA gene might play an important role in the resistance to fluoroquinolones.
\end{abstract}

Keywords: Salmonella, Prevalence, Serotype, Antimicrobial resistance, Diarrhea

\section{Background}

Salmonella is a main foodborne and waterborne pathogen worldwide which causes an annual death of 230,000 [1]. Salmonella-associated foodborne outbreaks were transmitted by contaminated food such as beef, pork, tomato, and cucumbers [2-5]. It was prevalent throughout the year, but was the most commonly detected between

\footnotetext{
* Correspondence: 595117459@qq.com

'Shenzhen Hospital, Southern Medical University, Xinhu Road 1333, Baoan District, Shenzhen 518110, Guangdong, China

Full list of author information is available at the end of the article
}

April and October in China [6]. Children less than 5 years old accounted for the largest proportion of infections $[7,8]$.

Over 2500 serotypes have been reported [9], with Enteritidis and Typhimurium being the most common serotypes causing gastroenteritis [10]. Salmonella isolates with different serotypes vary in the pathogenicity, prevalence, and sensitivity to antibiotics. Salmonella Typhi and Salmonella Paratyphi are usually associated with higher mortality [11]. Some serotypes were reported in only single region of the world, such as

C C The Author(s). 2020 Open Access This article is licensed under a Creative Commons Attribution 4.0 International License, which permits use, sharing, adaptation, distribution and reproduction in any medium or format, as long as you give appropriate credit to the original author(s) and the source, provide a link to the Creative Commons licence, and indicate if changes were made. The images or other third party material in this article are included in the article's Creative Commons licence, unless indicated otherwise in a credit line to the material. If material is not included in the article's Creative Commons licence and your intended use is not permitted by statutory regulation or exceeds the permitted use, you will need to obtain permission directly from the copyright holder. To view a copy of this licence, visit http://creativecommons.org/licenses/by/4.0/ The Creative Commons Public Domain Dedication waiver (http://creativecommons.org/publicdomain/zero/1.0/) applies to the data made available in this article, unless otherwise stated in a credit line to the data. 
Salmonella Rissen and Salmonella Weltevreden were only identified in Asia [12, 13]. Multi-drug resistance was the most common in $S$. Typhimurium [14].

Salmonellosis is not a severe infection, but the emergence of third-generation cephalosporins and multi-drug resistant isolates has raised concerns $[15,16]$. The wide use of antibiotics in poultry and for empirical treatment of salmonellosis has led to the rising of drug resistance rate of Salmonella. A high resistance rate to at least one class of clinically important antimicrobials including quinolones was found in the clinical and animal-derived (chicken and pork) isolates [16, 17]. A wide range of mechanisms were associated with cephalosporins and quinolone resistance, including mutation in the quinolone-resistance determining regions (QRDRs), over-expression of an efflux pump and acquisition of drug resistance plasmids [18].

A one-year surveillance was conducted in our previous research and Salmonella was found one of the main causes (12.1\%) of acute infectious diarrhea in Shenzhen [19]. Nevertheless, the long-term trend of serotype distribution and antimicrobial resistance pattern of the Salmonella isolates were not defined. To improve our understanding of the prevalence of Salmonella in this region and thus provide basis for designing prevention and control strategies, we investigated the serotypes and antibiotic resistance of the isolates obtained from the surveillance network during 2013 and 2018.

\section{Results}

\section{Sample information}

A total of 5239 cases (2749 of whom were male) were included during study period. Among these patients, 3870, 425, and 944 cases were enrolled from PKUSZH, $\mathrm{SCH}$, and $\mathrm{SYSU} 8 \mathrm{H}$, respectively. $\mathrm{SCH}$ and $\mathrm{SYSU} 8 \mathrm{H}$ started participating in the surveillance in 2016 and SCH was only involved in 2016. Patients ranged in age from 0 to 96 years (median 30 years). Local population who have registered permanent residence accounted for $60.4 \%$ of the patients. Of all the patients, $310(5.9 \%)$ had fever, $635(12.1 \%)$ had vomiting, and $50(1.0 \%)$ had blood in stools, respectively. Of the patients over 5 years old, 2098 (54.1\%) had abdominal pain (Table 1). Overall, Salmonella was isolated from 297 (5.7\%) of all cases. The recovery rate in $\mathrm{SCH}, \mathrm{PKUSZH}$, and $\mathrm{SYSU} 8 \mathrm{H}$ was $13.6 \%, 4.3 \%$, and $7.7 \%$, respectively.

\section{Serotyping results}

A total of 42 serotypes were identified in the 285 Salmonella isolates and additional 12 strains were untypable. Typhimurium $(118,39.7 \%)$ was the most common serotype, followed by serotype Enteritidis (71, 23.9\%), London (12, 4.0\%), 4, 5, 12: i: - (11, 3.7\%), and Senftenberg $(8,2.7 \%)$. A total of 46 isolates with
Table 1 The epidemiological and clinical characteristics of samples $(n=5239)$ in this study

\begin{tabular}{lll}
\hline Category & Subcategory & No. (\%) \\
\hline Year & 2013 & $931(17.8)$ \\
& 2014 & $793(15.1)$ \\
& 2015 & $652(12.5)$ \\
& 2016 & $1285(24.5)$ \\
& 2017 & $887(16.9)$ \\
& 2018 & $691(13.2)$ \\
& $<5$ & $1361(26.0)$ \\
Age (years) & $5 \sim 9$ & $73(1.4)$ \\
& $10 \sim 19$ & $217(4.1)$ \\
& $20 \sim 29$ & $847(16.2)$ \\
& $30 \sim 39$ & $984(18.8)$ \\
& $40 \sim 49$ & $683(13.0)$ \\
& $50 \sim 59$ & $496(9.5)$ \\
& $>=60$ & $578(11.0)$ \\
& Abdominal pain & $2098(54.1)^{a}$ \\
& Fever & $310(5.9)$ \\
Vomiting & $635(12.1)$ \\
Blood in stools & $50(1.0)$ \\
\hline
\end{tabular}

${ }^{a}$ Only 3878 cases aged over 5 years were included for analysis

uncommon serotypes were found, including serotype Virchow, Corvallis, Vilvoorde, and Sarajane (Table 2). A high recovery rate $(4.5 \%)$ of $S$. Typhimurium was observed in 2016 and onwards.

\section{Age and monthly distribution}

The highest detection rate was observed in the age group of $5 \sim 9$ years (15.1\%), followed by < 5 years $(10.1 \%)$ and $30 \sim 39$ years $(4.9 \%)$. The age group of over 60 years showed the lowest prevalence $(2.8 \%)$. A high prevalence of $S$. Typhimurium infection was seen in the young children aged less than 5 years $(6.4 \%)$ and $5 \sim 9$ years old (5.5\%). In the age group of $5 \sim 9$ years, serotype Enteritidis and 4, 5, 12: i: - were the other two common serotypes (Table 3 ).

Of the 118 S. Typhimurium isolates, 87 (73.7\%) were recovered from children aged below 5 years old. Eight of 11 serotype 4, 5, 12: i: - strains were isolated from this age group, while similar detection rate of $S$. Enteritidis strains was observed in each age group. Of the 72 isolates with other serotypes, 51 (70.8\%) were isolated from adults aged between 20 and 59 years old (Table 3).

The highest detection rate was seen in August (11.01\%), followed by September (8.56\%), June (8.49\%), and October (7.88\%). The detection rate between May and November $(8.19 \%)$ was significantly higher than that between December and April (1.89\%) $\left(X^{2}=93.440, P<\right.$ 
Table 2 The serotype distribution of clinical Salmonella isolates during 2013 and 2018

\begin{tabular}{|c|c|c|c|c|c|c|c|}
\hline \multirow[t]{2}{*}{ Serotype } & \multicolumn{6}{|c|}{ No. of isolates by year (recovery rate, \%) } & \multirow[b]{2}{*}{ Total $(n=5239$} \\
\hline & $2013(n=931)$ & $2014(n=793)$ & $2015(n=652)$ & $2016(n=1285)$ & $2017(n=887)$ & $2018(n=691)$ & \\
\hline Typhimurium & $6(0.6)$ & $8(1.0)$ & $5(0.8)$ & $58(4.5)$ & $22(2.5)$ & $19(2.7)$ & $118(2.3)$ \\
\hline Enteritidis & $18(1.9)$ & $6(0.8)$ & $10(1.5)$ & $12(0.9)$ & $13(1.5)$ & $12(1.7)$ & $71(1.4)$ \\
\hline London & $2(0.2)$ & $3(0.4)$ & $2(0.3)$ & $1(0.1)$ & $4(0.5)$ & $0(0.0)$ & $12(0.2)$ \\
\hline 4, 5, 12: i: - & $0(0.0)$ & $3(0.4)$ & $0(0.0)$ & $6(0.5)$ & $0(0.0)$ & $2(0.3)$ & $11(0.2)$ \\
\hline Senftenberg & $1(0.1)$ & $6(0.8)$ & $0(0.0)$ & $0(0.0)$ & $0(0.0)$ & $1(0.1)$ & $8(0.2)$ \\
\hline Stanley & $0(0.0)$ & $3(0.4)$ & $0(0.0)$ & $1(0.1)$ & $1(0.1)$ & $2(0.3)$ & $7(0.1)$ \\
\hline Agona & $3(0.3)$ & $1(0.1)$ & $0(0.0)$ & $0(0.0)$ & $0(0.0)$ & $1(0.1)$ & $5(0.1)$ \\
\hline Litchfield & $0(0.0)$ & $0(0.0)$ & $5(0.8)$ & $0(0.0)$ & $0(0.0)$ & $0(0.0)$ & $5(0.1)$ \\
\hline Weltevreden & $3(0.3)$ & $0(0.0)$ & $0(0.0)$ & $0(0.0)$ & $0(0.0)$ & $1(0.1)$ & $4(0.1)$ \\
\hline Others & $6^{a}(0.6)$ & $2^{b}(0.3)$ & $11^{c}(1.7)$ & $7^{d}(0.5)$ & $10^{e}(1.1)$ & $8^{f}(1.2)$ & $44(0.8)$ \\
\hline Un-typable & $4(0.4)$ & $1(0.1)$ & $1(0.2)$ & $2(0.2)$ & $3(0.3)$ & $1(0.1)$ & $12(0.2)$ \\
\hline Total & $43(4.6)$ & $33(4.2)$ & $34(5.2)$ & $87(6.8)$ & $53(6.0)$ & $47(6.8)$ & $297(5.7)$ \\
\hline
\end{tabular}

${ }^{a}$ Two strains of serotype Derby, 1 Ruzizi, 1 Meleagridis, and 2 Regent were included.

b One isolate of serotype Gallinarum-pullorum and 1 Drogana were included.

' One strain of Essen, 2 Manchester, 1 Sinstorf, 1 Chester, 1 Chomedey, 1 Tshiongwe, 1 Chennai, 1 Rissen, 1 Papuana, and 1 Fillmore were included.

${ }^{\mathrm{d}}$ Two strains of serotype Virchow, 2 Nigeria, 1 Bovismorbificans, 1 Hidalgo, and 1 Amherstiana were included.

e Two strains of serotype Infantis, 1 Montevideo, 1 Bovismorbificans, 1 Chester, 2 Braenderup, 1 Kottbus, 1 Corvallis, and 1 Kentucky were included.

${ }^{f}$ One strain of serotype Rissen, 1 Hato, 1 Sarajane, 1 Chester, 1 Assinie, 1 Pomona, 1 Muenster, and 1 Vilvoorde were included.

0.001). Similar seasonal distribution was also observed in the serotype Typhimurium isolates (Fig. 1).

\section{Antimicrobial resistance profile}

The highest rate of resistance was found in ampicillin (139, 70.6\%), followed by piperacillin $(127,64.5 \%)$, tetracycline $(125,63.5 \%)$, streptomycin $(107,54.3 \%)$, cefazolin (87, 44.2\%), and sulphamethoxazole/trimethoprim (75, $38.1 \%)$. The resistance to ampicillin and tetracycline was observed in 81 (95.3\%) of $S$. Typhimurium isolates. Twenty-seven (93.1\%) of $S$. Enteritidis isolates were resistant to nalidixic acid (Table 4). Five out of $8 S$. Senftenberg isolates were susceptible to all the tested antibiotics. Among the 163 isolates resistant to three or more antimicrobial agents, 82 and 23 were found in $S$.
Typhimurium and S. Enteritidis isolates, respectively. The multiple antibiotic resistance (MAR) index of 123 isolates was over 0.21 . The highest MAR index (0.71) was found in a serogroup B un-typable strain.

Among the common serotypes, the lowest resistant rate was seen in $S$. Senftenberg. A significant higher frequency of resistance to penicillins, cephems (except for cefoxitin and ceftazidime), monobactams, tetracyclines, folate pathway inhibitors, and phenicols was observed in $S$. Typhimurium compared with that in other serotypes $(P<0.05)$, while resistant rate to nalidixic acid $\left(\chi^{2}=45.227, P<0.001\right)$ and nitrofurantoin $\left(\chi^{2}=28.897\right.$, $P<0.001)$ was significantly higher in $S$. Enteritidis. Resistance to third generation cephalosporins and carbapenems was not found, while a higher resistant rate to

Table 3 The serotype distribution of clinical Salmonella isolates in different age groups

\begin{tabular}{|c|c|c|c|c|c|c|c|c|c|}
\hline \multirow{2}{*}{$\begin{array}{l}\text { Age } \\
\text { group } \\
\text { (year) }\end{array}$} & \multirow{2}{*}{$\begin{array}{l}\text { No. of } \\
\text { tested }\end{array}$} & \multicolumn{7}{|c|}{ No. of isolates (prevalence, \%) } & \multirow[t]{2}{*}{ Total (\%) } \\
\hline & & $\begin{array}{l}\text { Serotype } \\
\text { Typhimurium }\end{array}$ & $\begin{array}{l}\text { Serotype } \\
\text { Enteritidis }\end{array}$ & $\begin{array}{l}\text { Serotype } \\
\text { 4, 5, 12: i: - }\end{array}$ & $\begin{array}{l}\text { Serotype } \\
\text { London }\end{array}$ & $\begin{array}{l}\text { Serotype } \\
\text { Senftenberg }\end{array}$ & $\begin{array}{l}\text { Serotype } \\
\text { Stanley }\end{array}$ & $\begin{array}{l}\text { Other } \\
\text { serotypes }\end{array}$ & \\
\hline$<5$ & 1361 & $87(6.4)$ & $17(1.2)$ & $8(0.6)$ & $5(0.4)$ & $1(0.1)$ & $4(0.3)$ & $15(1.1)$ & $137(10.1)$ \\
\hline $5 \sim 9$ & 73 & $4(5.5)$ & $6(8.2)$ & $1(1.4)$ & $0(0.0)$ & $0(0.0)$ & $0(0.0)$ & $0(0.0)$ & $11(15.1)$ \\
\hline $10 \sim 19$ & 217 & $0(0.0)$ & $4(1.8)$ & $0(0.0)$ & $1(0.5)$ & $1(0.5)$ & $0(0.0)$ & $3(1.4)$ & $9(4.1)$ \\
\hline $20 \sim 29$ & 847 & $7(0.8)$ & $14(1.7)$ & $0(0.0)$ & $0(0.0)$ & $3(0.4)$ & $1(0.1)$ & $11(1.3)$ & $36(4.3)$ \\
\hline $30 \sim 39$ & 984 & $9(0.9)$ & $14(1.4)$ & $0(0.0)$ & $1(0.1)$ & $2(0.2)$ & $0(0.0)$ & $22(2.2)$ & $48(4.9)$ \\
\hline $40 \sim 49$ & 683 & $3(0.4)$ & $4(0.6)$ & $1(0.1)$ & $3(0.4)$ & $1(0.1)$ & $1(0.1)$ & $11(1.6)$ & $24(3.5)$ \\
\hline $50 \sim 59$ & 496 & $3(0.6)$ & $6(1.2)$ & $1(0.2)$ & $0(0.0)$ & $0(0.0)$ & $0(0.0)$ & $6(1.2)$ & $16(3.2)$ \\
\hline$>=60$ & 578 & $5(0.9)$ & $6(1.0)$ & $0(0.0)$ & $2(0.3)$ & $0(0.0)$ & $1(0.2)$ & $2(0.3)$ & $16(2.8)$ \\
\hline total & 5239 & $118(2.3)$ & $71(1.4)$ & $11(0.2)$ & $12(0.2)$ & $8(0.2)$ & $7(0.1)$ & $70(1.3)$ & $297(5.7)$ \\
\hline
\end{tabular}




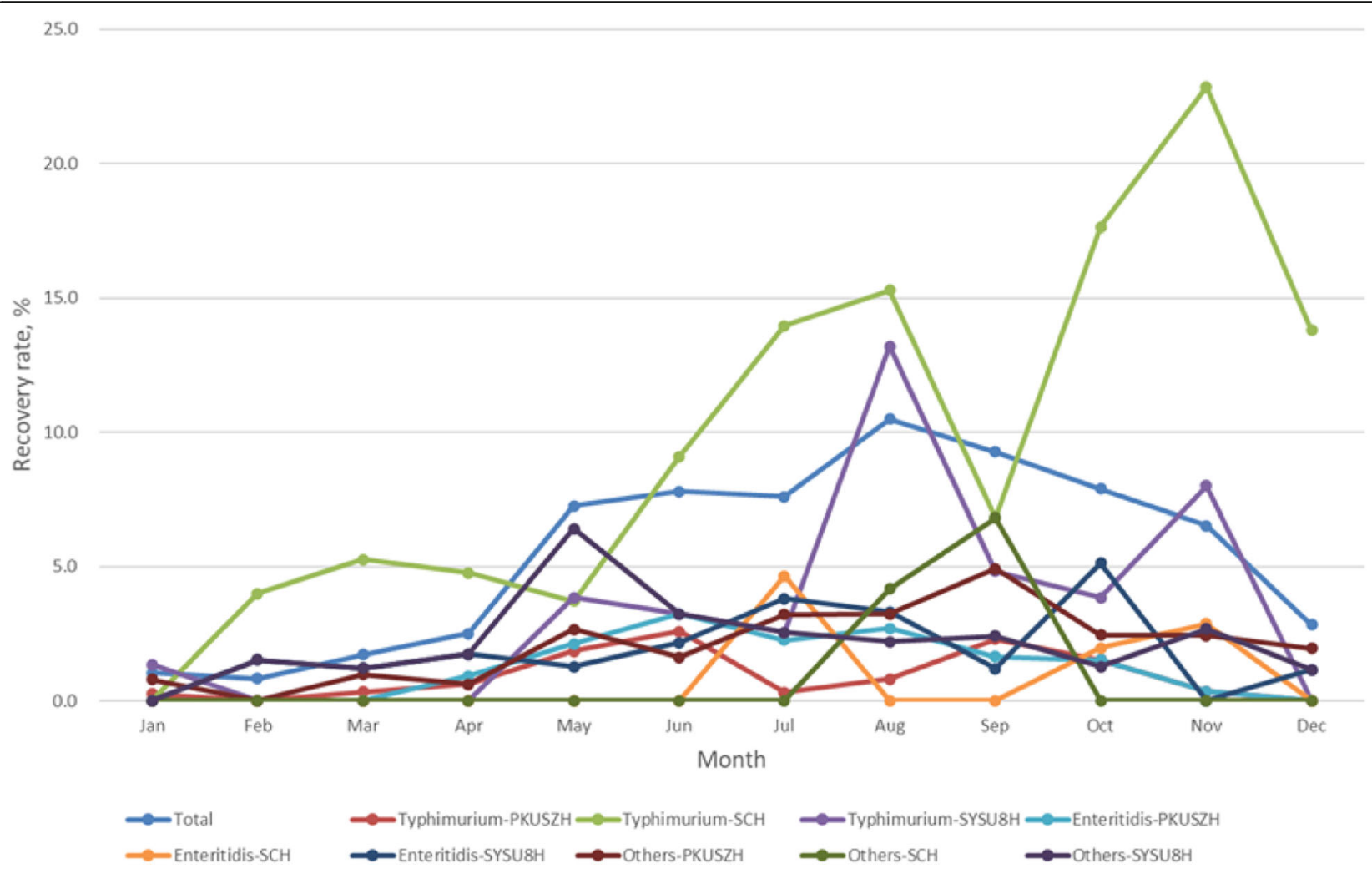

Fig. 1 The monthly distribution of clinical Salmonella isolates. PKUSZH, Peking University Shenzhen Hospital; SCH, Shenzhen Children's Hospital; SYSU8H, The Eighth Affiliated Hospital, Sun Yat-Sen University

ciprofloxacin and gentamicin was seen in $S$. London, compared with that in other serotypes (Table 4).

\section{Mutations with QRDRs}

The amino acid alterations in $g y r A$ occurred at codon 87 (Asp-87 $\rightarrow$ Gly or Asn) in 14 isolates and the MIC to CIP in 9 out of 14 isolates was over $2 \mu \mathrm{g} / \mathrm{ml}$. The mutation in $\operatorname{gyr} B$ occurred at codon 462 and 464, but no amino acid alteration was found (Leu-462 $\rightarrow$ Leu, Ser$464 \rightarrow$ Ser). A single base change in amino acids 67,75 , 77, 117, and 123 in parC were found in 5 of the tested strains. The mutation of codons 500 and 509 in parE was found in 3 and 8 isolates, respectively (Table 5).

\section{Discussion}

Salmonella was an important causative microorganism of acute gastroenteritis, which was shown in the detection rate during 2013 and 2018 (4.2\% 6.8\%). The detection rate was lower compared with that in our previous study (12.1\%) which incorporated PCR method [19], but it was comparable to another study (4.8\%) conducted in Guangzhou using conventional assay [20]. A detection rate of $4.5 \%$ was reported in a large laboratory-based surveillance study in Guangdong province during 2009 and 2012, suggesting the continued prevalence in this region [17].

A broad distribution of serotypes was also reported in another study conducted in Shenzhen [21]. Apart from the detection rate, this study provided the trend of prevalence and antimicrobial resistance data over a long period, and identified some rare serotypes.

The detection rate between May and November was significantly higher compared with that in other months, which might be associated with high temperature. Hot weather contributed to bacterial growth and the chance of consumption of insufficiently heat-treated food or salad was higher. A linear association between temperature and the number of reported cases of salmonellosis was found and it was proven that higher temperature was associated with Salmonella infections [22]. As a result, the sporadic cases and salmonellosis outbreak were commonly found during this period [17].

The high incidence of Salmonella infection in children was consistent with another study where a recovery rate of $17.2 \%$ in children was reported [15]. The high frequency of infections in children could be attributed to the behavior such as frequent contact with contaminated limbs, consumption of contaminated food or water, or close contacts with an asymptomatic caretaker [20]. S. 
Table 4 The antimicrobial susceptibility profiles of Salmonella isolates with different serotypes

\begin{tabular}{|c|c|c|c|c|c|c|}
\hline \multirow[t]{2}{*}{ Antimicrobial agent } & \multicolumn{6}{|c|}{ No. of resistant isolates by serotypes (resistant rate, \%) } \\
\hline & $\begin{array}{l}\text { Typhimurium } \\
(n=85)\end{array}$ & $\begin{array}{l}\text { Enteritidis } \\
(n=29)\end{array}$ & $\begin{array}{l}\text { London } \\
(n=5)\end{array}$ & $\begin{array}{l}\text { Senftenberg } \\
(n=8)\end{array}$ & $\begin{array}{l}\text { Others } \\
(n=70)\end{array}$ & $\begin{array}{l}\text { Total } \\
(n=197)\end{array}$ \\
\hline \multicolumn{7}{|l|}{ Penicillins } \\
\hline ampicillin & $81(95.3)$ & $22(75.9)$ & $2(40.0)$ & $0(0.0)$ & $34(48.6)$ & 139 (70.6) \\
\hline piperacillin & $74(87.1)$ & $21(72.4)$ & $2(40.0)$ & $0(0.0)$ & $30(42.9)$ & $127(64.5)$ \\
\hline \multicolumn{7}{|l|}{$\beta$-lactam $/ \beta$-lactamase inhibitors } \\
\hline ampicillin/ sulbactam & $9(10.6)$ & $7(24.1)$ & $0(0.0)$ & $1(12.5)$ & $6(8.6)$ & $23(11.7)$ \\
\hline \multicolumn{7}{|l|}{ Cephems } \\
\hline cefazolin & $50(58.8)$ & $16(55.2)$ & $1(20.0)$ & $1(12.5)$ & $19(27.1)$ & $87(44.2)$ \\
\hline cefepime & $23(27.1)$ & $5(17.2)$ & $0(0.0)$ & $0(0.0)$ & $9(12.9)$ & $37(18.8)$ \\
\hline cefotaxime & $40(47.1)$ & $8(27.6)$ & $0(0.0)$ & $1(12.5)$ & $15(21.4)$ & $64(32.5)$ \\
\hline ceftriaxone & $42(49.4)$ & $9(31.0)$ & $0(0.0)$ & $1(12.5)$ & $14(20.0)$ & 66 (33.5) \\
\hline cefoxitin & $3(3.5)$ & $2(6.9)$ & $0(0.0)$ & $1(12.5)$ & $1(1.4)$ & 7 (3.6) \\
\hline ceftazidime & $13(15.3)$ & $3(10.3)$ & $0(0.0)$ & $0(0.0)$ & $7(10.0)$ & $23(11.7)$ \\
\hline \multicolumn{7}{|l|}{ Monobactams } \\
\hline aztreonam & $23(27.1)$ & $3(10.3)$ & $0(0.0)$ & $0(0.0)$ & $9(12.9)$ & $35(17.8)$ \\
\hline \multicolumn{7}{|l|}{ Aminoglycosides } \\
\hline gentamicin & $22(25.9)$ & $0(0.0)$ & $3(60.0)$ & $0(0.0)$ & $13(18.6)$ & $38(19.3)$ \\
\hline amikacin & $2(2.4)$ & $0(0.0)$ & $0(0.0)$ & $0(0.0)$ & $0(0.0)$ & $2(1.0)$ \\
\hline streptomycin & $57(67.1)$ & $20(69.0)$ & $2(40.0)$ & $1(12.5)$ & $27(38.6)$ & $107(54.3)$ \\
\hline \multicolumn{7}{|l|}{ Carbapenems } \\
\hline imipenem & $3(3.5)$ & $0(0.0)$ & $0(0.0)$ & $0(0.0)$ & $1(1.4)$ & $4(2.0)$ \\
\hline meropenem & $2(2.4)$ & $0(0.0)$ & $0(0.0)$ & $0(0.0)$ & $0(0.0)$ & $2(1.0)$ \\
\hline \multicolumn{7}{|l|}{ Tetracyclines } \\
\hline tetracycline & $81(95.3)$ & $3(10.3)$ & $2(40.0)$ & $0(0.0)$ & $39(55.7)$ & $125(63.5)$ \\
\hline \multicolumn{7}{|l|}{ Quinolones and Fluoroquinolones } \\
\hline ciprofloxacin & $7(8.2)$ & $2(6.9)$ & $2(40.0)$ & $0(0.0)$ & $8(11.4)$ & $19(9.6)$ \\
\hline levofloxacin & $5(5.9)$ & $1(3.4)$ & $0(0.0)$ & $0(0.0)$ & $6(8.6)$ & $12(6.1)$ \\
\hline norfloxacin & $7(8.2)$ & $0(0.0)$ & $0(0.0)$ & $0(0.0)$ & $3(4.3)$ & $10(5.1)$ \\
\hline nalidixic acid & $26(30.6)$ & $27(93.1)$ & $3(60.0)$ & $0(0.0)$ & $18(25.7)$ & $74(37.6)$ \\
\hline \multicolumn{7}{|l|}{ Folate pathway inhibitors } \\
\hline sulphamethoxazole/trimethoprim & $42(49.4)$ & $4(13.8)$ & $2(40.0)$ & $1(12.5)$ & $26(37.1)$ & $75(38.1)$ \\
\hline trimethoprim & $38(44.7)$ & $3(10.3)$ & $2(40.0)$ & $0(0.0)$ & $22(31.4)$ & $65(33.0)$ \\
\hline \multicolumn{7}{|l|}{ Phenicols } \\
\hline Chloramphenicol & $41(48.2)$ & $2(6.9)$ & $1(20.0)$ & $0(0.0)$ & $21(30.0)$ & $65(33.0)$ \\
\hline \multicolumn{7}{|l|}{ Nitrofurans } \\
\hline nitrofurantoin & $2(2.4)$ & $11(37.9)$ & $0(0.0)$ & $0(0.0)$ & $8(11.4)$ & $21(10.7)$ \\
\hline \multicolumn{7}{|l|}{ MAR index } \\
\hline$<0.08$ & $0(0.0)$ & $3(10.3)$ & $2(40.0)$ & $6(72.5)$ & $23(32.9)$ & 34 (17.3) \\
\hline $0.08-$ & $3(3.5)$ & $3(10.3)$ & $0(0.0)$ & $1(12.5)$ & $5(7.1)$ & $12(6.1)$ \\
\hline $0.13-$ & $5(5.9)$ & $1(3.4)$ & $1(20.0)$ & $0(0.0)$ & $3(4.3)$ & $10(5.1)$ \\
\hline $0.17-$ & 10 (11.8) & $2(6.9)$ & $0(0.0)$ & $1(12.5)$ & $5(7.1)$ & $18(9.1)$ \\
\hline$\geq 0.21$ & 67 (78.8) & $20(69.0)$ & $2(40.0)$ & $0(0.0)$ & 34 (48.6) & $123(62.4)$ \\
\hline
\end{tabular}


Table 5 The linkage of QRDRs mutations with antimicrobial susceptibility profile

\begin{tabular}{|c|c|c|c|c|c|c|c|c|}
\hline \multirow{2}{*}{$\begin{array}{l}\text { Isolate } \\
\text { No. }\end{array}$} & \multirow[t]{2}{*}{ Serotype } & \multirow[t]{2}{*}{ MAR } & \multicolumn{2}{|c|}{ MIC $(\mu \mathrm{g} / \mathrm{ml})$} & \multicolumn{4}{|c|}{ Mutations-changes in codons } \\
\hline & & & $\overline{C I P}$ & LEV & gyrA & gyrB & parC & parE \\
\hline 1 & Typhimurium & 0.33 & $\begin{array}{l}<= \\
0.25\end{array}$ & $\begin{array}{l}<= \\
0.12\end{array}$ & - & - & - & - \\
\hline 2 & Typhimurium & 0.46 & 0.5 & 0.5 & - & - & - & - \\
\hline 3 & Typhimurium & 0.63 & 1 & 2 & - & $\begin{array}{l}\mathrm{CTT} \rightarrow \mathrm{CTC}, \mathrm{TCC} \rightarrow \\
\mathrm{TCT}^{\mathrm{C}}\end{array}$ & $\begin{array}{l}\mathrm{GTT} \rightarrow \mathrm{GTC}, \mathrm{CAC} \rightarrow \mathrm{CAT}, \mathrm{CAT} \rightarrow \mathrm{CAC}, \\
\mathrm{GCG} \rightarrow \mathrm{GCA}, \mathrm{TCC} \rightarrow \mathrm{TC} \mathbf{T}^{\mathrm{d}}\end{array}$ & $\begin{array}{l}\mathrm{ACT} \rightarrow \mathrm{ACG}^{\mathrm{e}}, \mathrm{CAC} \rightarrow \\
\mathrm{CAT}^{\mathrm{f}}\end{array}$ \\
\hline 4 & Bovismorbificans & 0.38 & 1 & 0.5 & $\begin{array}{l}\mathrm{GAC} \rightarrow \\
\mathrm{GGC}\end{array}$ & $\begin{array}{l}\mathrm{CTT} \rightarrow \mathrm{CTC}, \mathrm{TCC} \rightarrow \\
\mathrm{TCT}\end{array}$ & - & $\mathrm{ACT}, \mathrm{CAC} \rightarrow \mathrm{CAT}$ \\
\hline 5 & Typhimurium & 0.50 & 1 & 0.5 & $\begin{array}{l}\mathrm{GAC} \rightarrow \\
\mathrm{GGC}\end{array}$ & $\begin{array}{l}\mathrm{CTT} \rightarrow \mathrm{CTC}, \mathrm{TCC} \rightarrow \\
\mathrm{TCT}\end{array}$ & - & $\mathrm{ACT}, \mathrm{CAC} \rightarrow \mathrm{CAT}$ \\
\hline 6 & Enteritidis & 0.33 & 0.5 & 2 & - & $\begin{array}{l}\mathrm{CTT} \rightarrow \mathrm{CTC}, \mathrm{TCC} \rightarrow \\
\mathrm{TCT}\end{array}$ & - & $\mathrm{ACT}, \mathrm{CAC} \rightarrow \mathrm{CAT}$ \\
\hline 7 & London & 0.33 & 1 & 1 & - & $\begin{array}{l}\mathrm{CTT} \rightarrow \mathrm{CTC}, \mathrm{TCC} \rightarrow \\
\mathrm{TCT}\end{array}$ & $\begin{array}{l}\mathrm{GTT} \rightarrow \mathrm{GTC}, \mathrm{CAC} \rightarrow \mathrm{CAT}, \mathrm{CAT} \rightarrow \mathrm{CAC}, \\
\mathrm{GCG} \rightarrow \mathrm{GCA}, \mathrm{TCC} \rightarrow \mathrm{TCT}\end{array}$ & $\mathrm{ACT}, \mathrm{CAC} \rightarrow \mathrm{CAT}$ \\
\hline 8 & Typhimurium & 0.33 & 2 & 1 & $\begin{array}{l}\mathrm{GAC} \rightarrow \\
\mathrm{AAC}\end{array}$ & - & - & - \\
\hline 9 & Agona & 0.63 & 1 & 1 & - & $\begin{array}{l}\mathrm{CTT} \rightarrow \mathrm{CTC}, \mathrm{TCC} \rightarrow \\
\mathrm{TCT}\end{array}$ & $\begin{array}{l}\mathrm{GTT} \rightarrow \mathrm{GTC}, \mathrm{CAC} \rightarrow \mathrm{CAT}, \mathrm{CAT} \rightarrow \mathrm{CAC}, \\
\mathrm{GCG} \rightarrow \mathrm{GCA}, \mathrm{TCC} \rightarrow \mathrm{TC} \mathbf{T}\end{array}$ & $\begin{array}{l}\mathrm{ACT} \rightarrow \mathrm{ACG}, \mathrm{CAC} \rightarrow \\
\mathrm{CAT}\end{array}$ \\
\hline 10 & London & 0.42 & 1 & 1 & $\begin{array}{l}\mathrm{GAC} \rightarrow \\
\mathrm{AAC}\end{array}$ & $\begin{array}{l}\mathrm{CTT} \rightarrow \mathrm{CTC}, \mathrm{TCC} \rightarrow \\
\mathrm{TCT}\end{array}$ & $\begin{array}{l}\mathrm{GTT} \rightarrow \mathrm{GTC}, \mathrm{CAC} \rightarrow \mathrm{CAT}, \mathrm{CAT} \rightarrow \mathrm{CAC}, \\
\mathrm{GCG} \rightarrow \mathrm{GCA}, \mathrm{TCC} \rightarrow \mathrm{TCT}\end{array}$ & - \\
\hline 11 & Litchfield & 0.25 & 1 & 1 & $\begin{array}{l}\mathrm{GAC} \rightarrow \\
\mathrm{AAC}\end{array}$ & $\begin{array}{l}\mathrm{CTT} \\
\mathrm{TCT}\end{array} \rightarrow \mathrm{CTC}, \mathrm{TCC} \rightarrow$ & - & - \\
\hline 12 & $4,5,12$, i: - & 0.21 & 1 & 1 & - & - & - & - \\
\hline 13 & Enteritidis & 0.08 & 1 & 1 & $\begin{array}{l}\mathrm{GAC} \rightarrow \\
\mathrm{AAC}\end{array}$ & $\begin{array}{l}\mathrm{CTT} \rightarrow \mathrm{CTC}, \mathrm{TCC} \rightarrow \\
\mathrm{TCT}\end{array}$ & - & $\mathrm{ACT}, \mathrm{CAC} \rightarrow \mathrm{CAT}$ \\
\hline 14 & London & 0.13 & 2 & 0.5 & $\begin{array}{l}\mathrm{GAC} \rightarrow \\
\mathrm{AAC}\end{array}$ & $\begin{array}{l}\mathrm{CTT} \rightarrow \mathrm{CTC}, \mathrm{TCC} \rightarrow \\
\mathrm{TCT}\end{array}$ & $\begin{array}{l}\mathrm{GTT} \rightarrow \mathrm{GTC}, \mathrm{CAC} \rightarrow \mathrm{CAT}, \mathrm{CAT} \rightarrow \mathrm{CAC}, \\
\mathrm{GCG} \rightarrow \mathrm{GCA}, \mathrm{TCC} \rightarrow \mathrm{TC} \mathbf{T}\end{array}$ & $\begin{array}{l}\mathrm{ACT} \rightarrow \mathrm{ACG}, \mathrm{CAC} \rightarrow \\
\mathrm{CAT}\end{array}$ \\
\hline 15 & $4,5,12$, i: - & 0.50 & 2 & 2 & $\begin{array}{l}\mathrm{GAC} \rightarrow \\
\mathrm{AAC}\end{array}$ & - & - & - \\
\hline 16 & untypable & 0.42 & 2 & 4 & $\begin{array}{l}\mathrm{GAC} \rightarrow \\
\mathrm{AAC}\end{array}$ & - & - & - \\
\hline 17 & $4,5,12$, i: - & 0.42 & $>=4$ & 4 & $\begin{array}{l}\mathrm{GAC} \rightarrow \\
\mathrm{AAC}\end{array}$ & - & - & - \\
\hline 18 & Typhimurium & 0.42 & 2 & 2 & $\begin{array}{l}\mathrm{GAC} \rightarrow \\
\mathrm{AAC}\end{array}$ & - & - & - \\
\hline 19 & Typhimurium & 0.63 & $>=4$ & $>=8$ & $\begin{array}{l}\mathrm{GAC} \rightarrow \\
\mathrm{AAC}\end{array}$ & - & - & - \\
\hline 20 & Typhimurium & 0.46 & 2 & 4 & $\begin{array}{l}\mathrm{GAC} \rightarrow \\
\mathrm{AAC}\end{array}$ & - & - & - \\
\hline 21 & Typhimurium & 0.58 & $>=4$ & 4 & $\begin{array}{l}\mathrm{GAC} \rightarrow \\
\mathrm{AAC}\end{array}$ & - & - & - \\
\hline
\end{tabular}

Base pair changes in bold type.

MIC minimum inhibitory concentration, CIP ciprofloxacin, LEV levofloxacin.

- No mutation

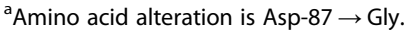

${ }^{\mathrm{b}}$ Amino acid alteration is Asp-87 $\rightarrow$ Asn.

${ }^{\mathrm{C} A m i n o}$ acid alterations are Leu- $462 \rightarrow$ Leu, Ser-464 $\rightarrow$ Ser.

${ }^{\mathrm{d}}$ Amino acid alterations are $\mathrm{Val}-67 \rightarrow \mathrm{Val}, \mathrm{His}-75 \rightarrow \mathrm{His}$, His-77 $\rightarrow \mathrm{His}, \mathrm{Ala}-117 \rightarrow \mathrm{Ala}$, Ser-123 $\rightarrow$ Ser.

${ }^{\mathrm{e}}$ Amino acid alteration is Thr- $500 \rightarrow$ Thr

${ }^{f}$ Amino acid alteration is His-509 $\rightarrow$ His.

Typhimurium and $S$. Enteritidis were the most common serotypes in children aged below 5 years old, which represented $75.4 \%(104 / 138)$ of the isolates, in accordance with other studies $[15,17]$. The high occurrence of $S$.
Typhimurium in the age group of $<5$ years and $5 \sim 9$ years might be associated with relatively low immune response and behaviors of these young children [23]. Highest recovery rate and highest occurrence of $S$. 
Enteritidis in the age group of $5 \sim 9$ years was probably due to the small sample size. The high frequency of multi-drug resistance in $S$. Typhimurium posed the difficulties in treating pediatric patients. Some measures such as good hygiene, proper hand washing, and education of their guardians were recommended to reduce the disease burden of salmonellosis in children.

Wide distribution of serotypes might be another reason of the continued prevalence of Salmonella infections. Apart from $S$. Typhimurium and $S$. Enteritidis, a broad range of uncommon serotypes including Vilvoorde and Sarajane were identified, indicating the wide sources of Salmonella. As one of the major pathogenic bacteria in Chinese food commodities [24], Salmonella was commonly isolated from beef, pork, and poultry meat $[25,26]$. Agona, Corvallis, and Kentucky were reported the dominant serotypes in chicken samples, while Typhimurium, Rissen, and Derby were the most common in pork samples [16]. The dominant presence of $S$. Typhimurium in 2016 and onwards was attributed to the participation of SCH and SYSU8H after 2016. Thirty-six of $S$. Typhimurium strains were isolated from PKUSZH, while 82 isolates were from the other two hospitals.

Serotype Gallinarum-pullorum was isolated from a 24year-old male patient with mild diarrhea. S. Gallinarumpullorum was generally regarded as chicken-derived which caused little public health concern. However, occasional infections in human were reported following consumption of heavily contaminated food and low detection rate was found in humans between 1982 and 1992 [27]. Transient illness caused by large number of $S$. Gallinarum-pullorum was observed in both volunteers [28] and our case. The contaminated raw meat was not considered as a food safety risk due to the thorough cooking tradition, but it was often associated with direct exposure to enteric pathogens and cross-contamination of ready-to-eat foods [29]. As a result, contamination from food handlers, or the consumption of contaminated or cross contaminated food may lead to the Salmonella infections.

Salmonella infections are normally associated with self-limiting diarrhea and antimicrobial therapy is not indicated, but appropriate antimicrobial treatment could be life-saving in severe cases. In addition, antibiotic treatment with ciprofloxacin or fluoroquinolones was recommended for Salmonella infections in infants less than 3 months of age due to the high risk of bacteremia and extraintestinal complications [30,31]. The occurrence of multiple drug resistant strains raised the importance of antibiotics resistance surveillance. The high level of resistance to the first-line agents: ampicillin, sulphamethoxazole/trimethoprim, and chloramphenicol was also observed in other studies [20]. A similar profile was also found in the isolates from food-producing animals [32], suggesting the careful use of antibiotics in breeding industry was necessary.

The frequency of multiple drug resistance was common. Resistance to 5 or more antibiotics was commonly observed in $S$. Enteritidis (69.0\%) and S. Typhimurium (78.8\%). The occurrence of multidrug resistant (MDR) strains was reported to be associated with coexistence of resistance-related genes [14] and their transmission led to great difficulties in treatments. The resistance to firstline drugs of treating severe infections, such as thirdgeneration cephalosporins and fluoroquinolones was of clinical concerns. The emergence of MDR isolates and increasing resistance to important antibiotics suggested the prevention measures and ongoing surveillance of antibiotic resistance are needed to control the infections.

The resistance to ciprofloxacin was mediated by multiple mechanisms [33], and the main mechanism of mutations in QRDRs was investigated in this study. A high frequency of mutations in $\operatorname{gyr} A, \operatorname{gyr} B$, parC, and parE genes were found in the quinolone-resistant strains. The amino acid alterations in $g y r A$ was associated with high levels of MIC to CIP and LEV, suggesting that the mutations in gyrA played an important role in the drug resistance. It was also reported in other studies that mutations associated with quinolone resistance were mainly present in the QRDRs of gyrA gene [34,35], probably due to that the DNA gyrase was the primary target of quinolone action and a single point mutation of gyrA could lead to the reduced susceptibility to fluoroquinolones. In the isolates absence of chromosomal mutations where no amino acid alteration was found, other mechanisms such as overexpression of efflux pump and mutations of other elements might contribute to the resistance [36, 37].

\section{Conclusion}

1. Salmonella was an important causative microorganism of acute diarrhea in this region and a broad range of serotypes were prevalent.

2. S. Typhimurium and $S$. Enteritidis were the two most common serotypes. The highest detection rate was found in the age group of less than 9 years old and during June and October.

3. A high rate of MDR was found in serotype Typhimurium and Enteritidis. An increasing trend of resistant rate to fluoroquinolones was mainly associated with the point mutation in the QRDRs of gyrA gene.

\section{Methods}

\section{Stool samples collection}

Peking University Shenzhen Hospital (PKUSZH), Shenzhen Children's Hospital (SCH), and The Eighth 
Affiliated Hospital, Sun Yat-Sen University (SYSU8H) were selected as sentinel hospitals in this retrospective study. Stool samples were collected from outpatients who visited gastroenteritis clinic due to acute infectious diarrhea and agreed to take part in the surveillance program. Acute diarrhea was defined as over 3 passages of loose, mucus-, watery, or bloody-stools during 24-h period. The stool samples were examined for Salmonella sp. using CHROM agars. The clinical signs and demographic information were retrospectively collected from electronic medical records.

\section{Serotyping and antimicrobial susceptibility testing}

The stool specimens were enriched in selenite cysteine (SC) broth and then plated on CHROM agar for isolation of Salmonella spp.. The suspicious colonies were identified using Vitek-2 compact system (bioMerieux, France) and Salmonella spp. isolates were serotyped with a commercial serotyping kit (S\&A company, S\&A Reagent Lab, Bangkok, Thailand) in the sentinel hospitals. Then part of the isolates were sent to Futian District Center for Disease Control and Prevention (CDC) and Shenzhen Hospital, Southern Medical University and stored in $-80^{\circ} \mathrm{C}$ for further analysis.

A total of 197 collected Salmonella isolates representing 26 serotypes were recovered and tested for antimicrobial susceptibility in 2019. Twenty-four antimicrobials (Oxoid, UK) including amikacin (30 micrograms (mcg), AK), ampicillin/sulbactam (20 mcg, SAM), ampicillin (10 mcg, AMP), aztreonam (30 mcg, ATM), cefepime (30 mcg, FEP), cefotaxime (30 mcg, CTX), cefoxitin (30 mcg, FOX), ceftazidime (30 mcg, CAZ), ceftriaxone (30 mcg, CRO), cephazolin (30 mcg, KZ), chloramphenicol $(30 \mathrm{mcg}, \mathrm{C})$, ciprofloxacin (5 mcg, CIP), gentamicin (10 mcg, CN), imipenem (10 mcg, IPM), levofloxacin (5 mcg, LEV), meropenem (10 mcg, MEM), nalidixic acid (30 mcg, NA), nitrofurantoin (300 mcg, F), norfloxacin (10 mcg, NOR), piperacillin (100 mcg, PRL), streptomycin $(10 \mathrm{mcg}, \mathrm{S})$, sulphamethoxazole/trimethoprim (25 mcg, SXT), tetracycline $(30 \mathrm{mcg}, \mathrm{TE})$, and trimethoprim $(5 \mathrm{mcg}, \mathrm{W})$ were tested using disk diffusion method. The susceptibility to CIP and LEV in quinolone-resistant isolates was confirmed by Vitek- 2 compact system (bioMerieux, France).

The MacFarland 0.5 inoculums were prepared and swabbed on the entire surface of Mueller-Hinton agar (Huankai, China) and left to dry for 3-5 min. Antimicrobial susceptibility test discs (Oxoid, UK) were placed on the inoculated agar plate with a disc dispenser (Oxoid, UK) and incubated at $37^{\circ} \mathrm{C}$ for $24 \mathrm{~h}$. After incubation, the diameter of inhibition zone was measured and the results were interpreted as susceptible, intermediate, and resistant according to the Clinical and Laboratory Standards Institute guideline (CLSI, 2019) [38]. Escherichia coli strain ATCC 25922 and Pseudomonas aeruginosa strain ATCC 27853 was used as quality control for disk diffusion and Vitek-2 compact system, respectively.

The multiple antibiotic resistance (MAR) index was the ratio between the number of antibiotics to which the organism was resistant and the number of antibiotics tested. Multi-drug resistant (MDR) was defined as resistant to three or more different classes of antimicrobial agents. Statistical analysis was conducted using chi-square test by SPSS version 21 (SPSS Inc., Chicago, IL, USA).

\section{Detection of target gene mutations}

A total of 21 isolates that resistant to any of the three antibiotics: ciprofloxacin, levofloxacin, and norfloxacin were chosen to screen for the mutations of the $g y r A$, gyrB, parC, and parE genes in the QRDRs. The bacterial nucleic acid was extracted using QIAamp DNA Mini Kit (Qiagen GmbH, Hilden, Germany) and subjected to PCR amplification using Taq PCR Master Mix Kit (Qiagen $\mathrm{GmbH}$, Hilden, Germany), according to the manufacturer's recommended protocols. The PCR products were sent to Sangon (Shanghai, China) for sequencing and the results were analyzed using BLAST (PubMed). The primers used for PCR amplification and sequencing were listed in Supplementary Table $1[39,40]$.

\section{Supplementary information}

Supplementary information accompanies this paper at https://doi.org/10. 1186/s12866-020-01886-5.

Additional file 1: Table S1. List of primers used in this study.

\section{Abbreviations}

AMP: Ampicillin; AK: Amikacin; ATM: Aztreonam; C: Chloramphenicol; CAZ: Ceftazidime; CDC: Center for Disease Control and Prevention; CIP: Ciprofloxacin; CLSI: Clinical and Laboratory Standards Institute; CN: Gentamicin; CRO: Ceftriaxone; CTX: Cefotaxime; F: Nitrofurantoin; FEP: Cefepime; FOX: Cefoxitin; IPM: Impenem; KZ: Cephazolin;

LEV: Levofloxacin; MAR: Multiple antibiotic resistance; mcg: Micrograms; MDR: Multi-drug resistant; MEM: Meropenem; MIC: Minimum inhibitory concentration; NA: Nalidixic acid; NOR: Norfloxacin; PCR: Polymerase chain reaction; PKUSZH: Peking University Shenzhen Hospital; PRL: Piperacillin; QRDRs: Quinolone-resistance determining regions; S: Streptomycin; SAM: Ampicillin/sulbactam; SCH: Shenzhen Children's Hospital; SXT: Sulphamethoxazole/trimethoprim; SYSU8H: The Eighth Affiliated Hospital, Sun Yat-Sen University; TE: Tetracycline; W: Trimethoprim

\section{Acknowledgements}

We thank the staff from the clinical laboratory of Peking University Shenzhen Hospital, Shenzhen Children's Hospital, and The Eighth Affiliated Hospital, Sun Yat-Sen University who took part in the study.

\section{Authors' contributions}

$\mathrm{QH}$ and WM designed the study. HS, JZ, and YO collected and detected clinical samples. TH detected antibiotic resistance genes. HC, LZ, and SC collected and analyzed data. HS and WM drafted, and revised the

manuscript with YZ. All authors read and approved the final manuscript.

\section{Funding}

This research was supported by Natural Science Foundation of Guangdong Province (NO.2018A0303130119 and 2020A1515010009), Sanming Project of Medicine in Shenzhen (NO. SZSM201811071 and SZSM201612023), Futian District Public Health Research Project (NO. FTWS2019067 and 
FTWS2019073), Seeding Program of Shenzhen Hospital of Southern Medical University (NO.2016MM07 and 2018MM01), and Research Foundation of Shenzhen Hospital, Southern Medical University (PY202002YM and PY2020ZY09). We thank the staff from Peking University Shenzhen Hospital, Shenzhen Children's Hospital, and The Eighth Affiliated Hospital, Sun Yat-Sen University who participated in the study.

\section{Availability of data and materials}

The datasets used and analyzed during the current study are available from the corresponding authors on reasonable request.

\section{Ethics approval and consent to participate}

All aspects of the study were performed in accordance with national ethics regulations and approved by the Ethics Committees of the participated organizations, including Shenzhen Center for Disease Control and Prevention, Futian District Center for Disease Control and Prevention, and the sentinel hospitals. Participants received information regarding the purpose of this study and of their right to confidentiality. Written consent was obtained from the participants or the parents or guardians of the pediatric patients.

\section{Consent for publication}

Not applicable.

\section{Competing interests}

The authors declare that they have no competing interests.

\section{Author details}

'Shenzhen Hospital, Southern Medical University, Xinhu Road 1333, Baoan District, Shenzhen 518110, Guangdong, China. ${ }^{2}$ Futian District Center for Disease Control and Prevention, Hongli Xilu 8043, Futian District, Shenzhen 518040, China. ${ }^{3}$ Shenzhen Children's Hospital, Yitian Road 7019, Shenzhen 518038, China. ${ }^{4}$ Shenzhen Center for Disease Control and Prevention, Longyuan Road 8, Nanshan District, Shenzhen 518000, China.

Received: 16 April 2020 Accepted: 29 June 2020

Published online: 06 July 2020

\section{References}

1. Havelaar AH, Kirk MD, Torgerson PR, Gibb HJ, Hald T, Lake RJ, et al. World Health Organization global estimates and regional comparisons of the burden of foodborne disease in 2010. PLoS Med. 2015;12(12):e1001923. https://doi.org/10.1371/journal.pmed.1001923.

2. Jackson BR, Griffin PM, Cole D, Walsh KA, Chai SJ. Outbreak-associated Salmonella enterica serotypes and food commodities, United States, 19982008. Emerg Infect Dis. 2013;19(8):1239-44. https://doi.org/10.3201/eid1908. 121511.

3. Muller L, Kjelso C, Frank C, Jensen T, Torpdahl M, Soborg B, et al. Outbreak of Salmonella Strathcona caused by datterino tomatoes, Denmark, 2011. Epidemiol Infect. 2016;144(13):2802-11. https://doi.org/10.1017/ S0950268816000121.

4. Marshall KEH, Tewell M, Tecle S, Leeper M, Sinatra J, Kissler B, et al. Protracted Outbreak of Salmonella Newport Infections Linked to Ground Beef: Possible Role of Dairy Cows - 21 States, 2016-2017. MMWR Morb Mortal Wkly Rep. 2018;67(15):443-6. https://doi.org/10.15585/mmwr. mm6715a2.

5. Laughlin M, Bottichio L, Weiss J, Higa J, McDonald E, Sowadsky R, et al. Multistate outbreak of Salmonella Poona infections associated with imported cucumbers, 2015-2016. Epidemiol Infect. 2019;147:e270. https:// doi.org/10.1017/S0950268819001596.

6. Ran L, Wu S, Gao Y, Zhang X, Feng Z, Wang Z, et al. Laboratory-based surveillance of nontyphoidal Salmonella infections in China. Foodborne Pathog Dis. 2011;8(8):921-7. https://doi.org/10.1089/fpd.2010.0827.

7. Besser JM. Salmonella epidemiology: a whirlwind of change. Food Microbiol. 2018;71:55-9. https://doi.org/10.1016/j.fm.2017.08.018.

8. Chen C, Wang LP, Yu JX, Chen X, Wang RN, Yang XZ, et al. Prevalence of Enteropathogens in outpatients with acute diarrhea from urban and rural areas, Southeast China, 2010-2014. Am J Trop Med Hyg. 2019;101 (2):310-8. https://doi.org/10.4269/ajtmh.19-0171.

9. Su LH, Chiu CH. Salmonella: clinical importance and evolution of nomenclature. Chang Gung Med J. 2007;30(3):210-9.
10. Qi X, Li P, Xu X, Yuan Y, Bu S, Lin D. Epidemiological and molecular investigations on Salmonella responsible for gastrointestinal infections in the southwest of Shanghai from 1998 to 2017. Front Microbiol. 2019;10: 2025. https://doi.org/10.3389/fmicb.2019.02025.

11. Buckle GC, Walker CL, Black RE. Typhoid fever and paratyphoid fever: systematic review to estimate global morbidity and mortality for 2010. J Glob Health. 2012;2(1):010401. https://doi.org/10.7189/jogh.02.010401.

12. Hendriksen RS, Vieira AR, Karlsmose S. Lo Fo Wong DM, Jensen $A B$, Wegener $\mathrm{HC}$, et al. global monitoring of Salmonella serovar distribution from the World Health Organization global foodborne infections network country data Bank: results of quality assured laboratories from 2001 to 2007. Foodborne Pathog Dis. 2011;8(8):887-900. https://doi.org/ 10.1089/fpd.2010.0787.

13. Galanis E. Lo Fo Wong DM, Patrick ME, Binsztein N, Cieslik a, Chalermchikit T, et al. web-based surveillance and global Salmonella distribution, 20002002. Emerg Infect Dis. 2006;12(3):381-8. https://doi.org/10.3201/eid1205. 050854.

14. Wang J, Li Y, Xu X, Liang B, Wu F, Yang X, et al. Antimicrobial resistance of Salmonella enterica Serovar Typhimurium in Shanghai, China. Front Microbiol. 2017;8:510. https://doi.org/10.3389/fmicb.2017.00510.

15. Li Y, Xie X, Xu X, Wang X, Chang H, Wang C, et al. Nontyphoidal salmonella infection in children with acute gastroenteritis: prevalence, serotypes, and antimicrobial resistance in Shanghai, China. Foodborne Pathog Dis. 2014; 11(3):200-6. https://doi.org/10.1089/fpd.2013.1629.

16. Zhang L, Fu Y, Xiong Z, Ma Y, Wei Y, Qu X, et al. Highly prevalent multidrug-resistant Salmonella from chicken and pork meat at retail Markets in Guangdong, China. Front Microbiol. 2018;9:2104. https://doi.org/10.3389/ fmicb.2018.02104

17. Liang Z, Ke B, Deng X, Liang J, Ran L, Lu L, et al. Serotypes, seasonal trends, and antibiotic resistance of non-typhoidal Salmonella from human patients in Guangdong Province, China, 2009-2012. BMC Infect Dis. 2015;15:53. https://doi.org/10.1186/s12879-015-0784-4.

18. Eguale T, Birungi J, Asrat D, Njahira MN, Njuguna J, Gebreyes WA, et al. Genetic markers associated with resistance to beta-lactam and quinolone antimicrobials in non-typhoidal Salmonella isolates from humans and animals in Central Ethiopia. Antimicrob Resist Infect Control. 2017;6:13. https://doi.org/10.1186/s13756-017-0171-6.

19. Shen H, Zhang J, Li Y, Xie S, Jiang Y, Wu Y, et al. The 12 gastrointestinal pathogens Spectrum of acute infectious diarrhea in a sentinel hospital, Shenzhen, China. Front Microbiol. 2016;7:1926. https://doi.org/10.3389/ fmicb.2016.01926.

20. Liang B, Xie Y, He S, Mai J, Huang Y, Yang L, et al. Prevalence, serotypes, and drug resistance of nontyphoidal Salmonella among paediatric patients in a tertiary hospital in Guangzhou, China, 2014-2016. J Infect Public Health. 2019;12(2):252-7. https://doi.org/10.1016/j.jiph.2018.10.012.

21. Long LD, Wei HJ, WU SJ, Jiang PS, LI HJ, Zhuo F. Characteristics of drug resistance and molecular typing for Salmonella in diarrhea patients from four hospitals in Shenzhen. Chinese J Zoonoses. 2017;33(10):897-902.

22. Kovats RS, Edwards SJ, Hajat S, Armstrong BG, Ebi KL, Menne B. The effect of temperature on food poisoning: a time-series analysis of salmonellosis in ten European countries. Epidemiol Infect. 2004;132(3):443-53.

23. Broz P, Ohlson MB, Monack DM. Innate immune response to Salmonella typhimurium, a model enteric pathogen. Gut Microbes. 2012;3(2):62-70. https://doi.org/10.4161/gmic.19141.

24. Paudyal N, Pan H, Liao X, Zhang X, Li X, Fang W, et al. A meta-analysis of major foodborne pathogens in Chinese food commodities between 2006 and 2016. Foodborne Pathog Dis. 2018;15(4):187-97. https://doi.org/10. 1089/fpd.2017.2417.

25. Yang $X$, Wu Q, Zhang J, Huang J, Chen L, Wu S, et al. Prevalence, bacterial load, and antimicrobial resistance of Salmonella Serovars isolated from retail meat and meat products in China. Front Microbiol. 2019;10:2121. https://doi. org/10.3389/fmicb.2019.02121.

26. Li Y, Pei XY, Zhang XL, Wu LL, Liu Y, Zhou HD, et al. A surveillance of microbiological contamination on raw poultry meat at retail markets in China. Food Control. 2019;104:99-104. https://doi.org/10.1016/j.foodcont. 2019.04.037.

27. Shivaprasad HL. Fowl typhoid and pullorum disease. Rev Sci Tech. 2000; 19(2):405-24. https://doi.org/10.20506/rst.19.2.1222

28. Mc CN, Eisele CW. Experimental human salmonellosis. IV. Pathogenicity of strains of Salmonella pullorum obtained from spray-dried whole egg. J Infect Dis. 1951;89(3):259-65. https://doi.org/10.1093/infdis/89.3.259. 
29. Yang B, Xi M, Wang X, Cui S, Yue T, Hao H, et al. Prevalence of Salmonella on raw poultry at retail markets in China. J Food Prot. 2011;74(10):1724-8. https://doi.org/10.4315/0362-028X.JFP-11-215.

30. Bula-Rudas FJ, Rathore MH, Maraqa NF. Salmonella infections in childhood. Adv Pediatr Infect Dis. 2015;62(1):29-58. https://doi.org/10. 1016/j.yapd.2015.04.005.

31. Haeusler GM, Curtis N. Non-typhoidal Salmonella in children: microbiology, epidemiology and treatment. Adv Exp Med Biol. 2013;764:13-26. https://doi. org/10.1007/978-1-4614-4726-9_2

32. Lai J, Wu C, Wu C, Qi J, Wang Y, Wang H, et al. Serotype distribution and antibiotic resistance of Salmonella in food-producing animals in Shandong province of China, 2009 and 2012. Int J Food Microbiol. 2014;180:30-8. https://doi.org/10.1016/.i.jfoodmicro.2014.03.030

33. Wei Z, Xu X, Yan M, Chang H, Li Y, Kan B, et al. Salmonella Typhimurium and Salmonella Enteritidis infections in sporadic diarrhea in children: source tracing and resistance to third-generation Cephalosporins and ciprofloxacin. Foodborne Pathog Dis. 2019;16(4): 244-55. https://doi.org/10.1089/fpd.2018.2557.

34. Gopal M, Elumalai S, Arumugam S, Durairajpandian V, Kannan MA Selvam E, et al. GyrA ser83 and ParC trp106 mutations in Salmonella enterica Serovar Typhi isolated from typhoid fever patients in tertiary care hospital. J Clin Diagn Res. 2016;10(7):DC14-8. https://doi.org/10. 7860/JCDR/2016/17677.8153

35. Eaves DJ, Randall L, Gray DT, Buckley A, Woodward MJ, White AP, et al. Prevalence of mutations within the quinolone resistance-determining region of gyrA, gyrB, parC, and parE and association with antibiotic resistance in quinolone-resistant Salmonella enterica. Antimicrob Agents Chemother. 2004;48(10):4012-5. https://doi.org/10.1128/AAC.48.10.40124015.2004.

36. Lin D, Chen K, Wai-Chi Chan E, Chen S. Increasing prevalence of ciprofloxacin-resistant food-borne Salmonella strains harboring multiple PMQR elements but not target gene mutations. Sci Rep. 2015;5:14754. https://doi.org/10.1038/srep14754

37. Shen J, Yang B, Gu Q, Zhang G, Yang J, Xue F, et al. The role of AcrAB-TolC efflux pump in mediating Fluoroquinolone resistance in naturally occurring Salmonella isolates from China. Foodborne Pathog Dis. 2017;14(12):728-34. https://doi.org/10.1089/fpd.2017.2291.

38. Humphries RM, Abbott AN, Hindler JA. Understanding and addressing CLSI breakpoint revisions: a primer for clinical laboratories. J Clin Microbiol. 2019; 57(6). https://doi.org/10.1128/JCM.00203-19.

39. Fabrega A, du Merle L, Le Bouguenec C, Jimenez de Anta MT, Vila J. Repression of invasion genes and decreased invasion in a high-level fluoroquinolone-resistant Salmonella typhimurium mutant. PLoS One. 2009; 4(11):e8029. https://doi.org/10.1371/journal.pone.0008029.

40. Randall LP, Coldham NG, Woodward MJ. Detection of mutations in Salmonella enterica gyr A, gyrB, parC and parE genes by denaturing high performance liquid chromatography (DHPLC) using standard HPLC instrumentation. J Antimicrob Chemother. 2005;56(4):619-23. https://doi. org/10.1093/jac/dki293.

\section{Publisher's Note}

Springer Nature remains neutral with regard to jurisdictional claims in published maps and institutional affiliations.

Ready to submit your research? Choose BMC and benefit from:

- fast, convenient online submission

- thorough peer review by experienced researchers in your field

- rapid publication on acceptance

- support for research data, including large and complex data types

- gold Open Access which fosters wider collaboration and increased citations

- maximum visibility for your research: over $100 \mathrm{M}$ website views per year

At $\mathrm{BMC}$, research is always in progress.

Learn more biomedcentral.com/submissions 